\title{
Variation of the ozonosphere in the southern hemisphere in spring 2014 and 2015 based on satellite data
}

\author{
Valentine B. Kashkin*a, Alexander V. Dergunov ${ }^{\mathrm{b}}$, Tatyana V. Rubleva ${ }^{\mathrm{a}}$, Roman V. Odintsov ${ }^{\mathrm{a}}$ \\ ${ }^{a}$ Siberian Federal University, Svobodny str. 79, 660041, Russian Federation, ' Institute of \\ Computational Modeling of the Siberian Branch of the Russian Academy of Sciences, \\ Akademgorodok 50/44, 660036 Krasnoyarsk, Russian Federation
}

\begin{abstract}
Satellite data were used to study changes in the Antarctic ozone hole (AOH) in 2014 and 2015. The formation of $\mathrm{AOH}$ is probably caused by the ozone mass transport from the polar areas to the mid-latitudes of the Southern Hemisphere. In November-December, the AOH is filled with the ozone moving from the midlatitudes. In 2014, the ozone masses moving from the Polar region to the mid-latitudes and back were equal to each other, reaching over 70 million tons. No signs of ozone destruction were found in September - December 2014. In 2015, the difference between the ozone masses reached 70.9\%. The most likely reason for this was the destruction of the stratospheric ozone by the products of the eruption of Calbuco Volcano in Chile.
\end{abstract}

Keywords: space monitoring, satellite data, stratosphere, atmospheric dynamics, total ozone, ozone layer, Antarctic ozone hole, circumpolar vortex

\section{INTRODUCTION}

The state of Earth's ozone layer is among the major global environmental issues. The occurrence of the ozone hole above the Antarctic (AOH) in spring was discovered in the 1980 [1]. WMO defines the ozone hole (ozone anomaly) as an area of the stratosphere where the total ozone (TO) is below 220 Dobson units (DU, $1 \mathrm{DU}=10^{-5} \mathrm{~m}$ ). TO is the thickness of the layer of gaseous ozone in the vertical column of the atmosphere under normal conditions: temperature of $0^{\circ} \mathrm{C}$ and pressure of $1013 \mathrm{hPa}$. A vortex ring with increased TO is formed around the $\mathrm{AOH}$ in the middle latitudes of the Southern Hemisphere in springtime. The TO here may reach $450 \mathrm{DU}$ or even higher. The data reported by the NASA [2] suggest that from 1985 to 2018, the area of the ozone hole varied between 18 and 30 million $\mathrm{km}^{2}$, and the ozone mass deficit in the Antarctic ozone hole varied between 14 and $44 \mathrm{Mt}$. The lifespan of the AOH is 3-4 months, from the time when it is formed to the time when it is "filled".

The ozone layer has been monitored from space by satellite instruments such as SBUV, TOMS, OMI, SAGE, GOME, SCIAMANCHY, etc. The data have been chiefly retrieved from the TOMS (Nimbus-7, Метеop-3, Earth Probe) and OMI (Aura) satellite spectrometers. The scanners measure outgoing (reflected and backscattered) solar UV radiation. Satellite measurement error is no more than 2-4\% [3]. The daily ozone data from 1978 onwards are presented at the NASA site as digital maps with the latitude step of $1^{\circ}$ and the longitude step of $1^{\circ}\left(1.25^{\circ}\right)$ [4].

Stolarski and Schoeberl [5] put forward the hypothesis suggesting that during the formation of the AOH, ozone masses move from the Polar region of the Southern Hemisphere to the mid-latitudes, and, in late September, ozone masses begin to move back, poleward. The ozone layer above the Antarctic is recovered in November-December. The hypothesis was confirmed in a study by Kashkin et al. [6], and the same study discussed the mechanism of the springtime redistribution of the ozone masses in the Southern Hemisphere.

*rtcvbk@rambler.ru 


\section{TOTAL OZONE IN SPRING 2014 AND 2015}

The NASA site [4] provides TO zonal means: daily values of total ozone in $5^{\circ}$ latitude circles. The TO in each circle is longitude-averaged from 0 to 360 degrees. The methods of analyzing ozone mass transport from the mid-latitudes to the Antarctic polar region were described in another study [7].

The present work addresses variations in the TO zonal means in spring 2014 and 2015. The graphs of the latitude dependence of the zonal means in 2014 are shown in Figure 1. The "climate normal" for the AOH - 220 DU - is shown with a dashed line.

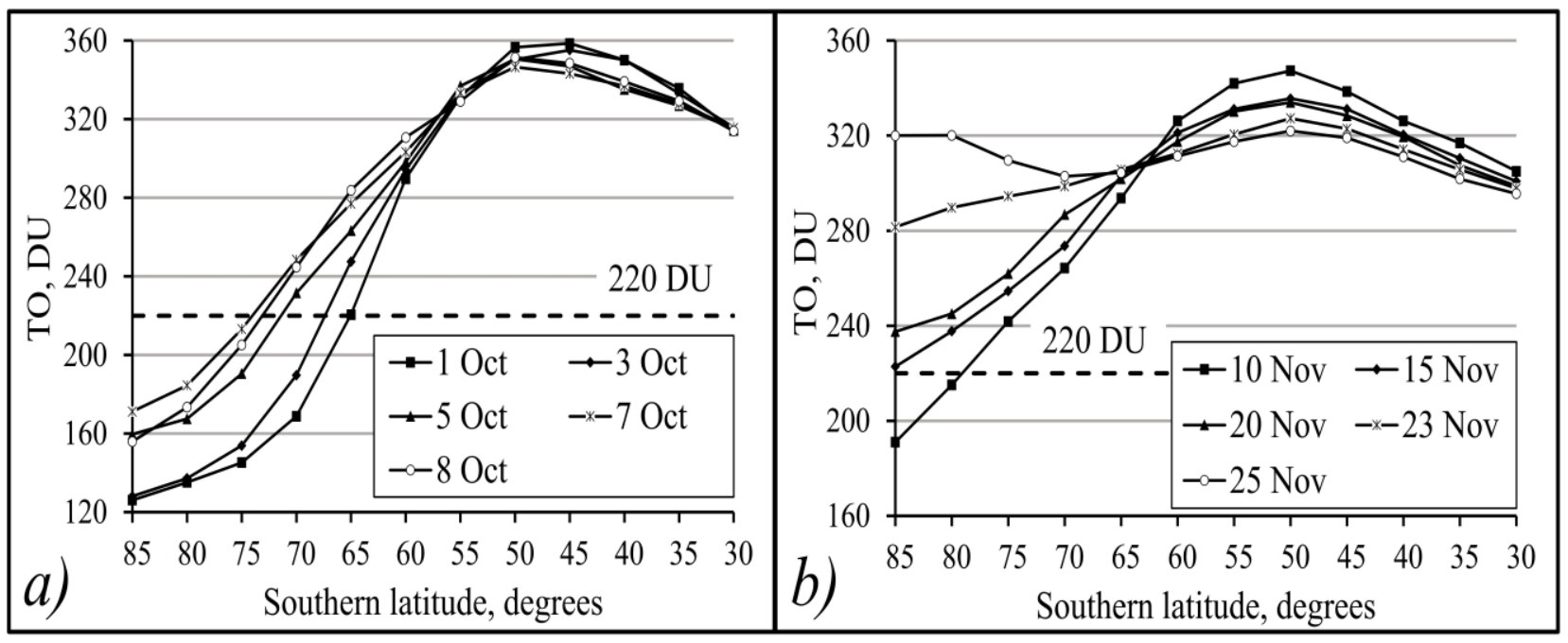

Figure 1.Variations in TO zonal means in October $(a)$ and November $(b) 2014$

In October, in the $65^{\circ} \mathrm{S}-85^{\circ} \mathrm{S}$ region, total ozone decreases and an ozone anomaly is formed (Fig. $1, a$ ). There is a vortex ring in the mid-latitudes, with increased $\mathrm{TO}$ and the maximum at $40^{\circ} \mathrm{S}-55^{\circ} \mathrm{S}$. Figure $1, b$ shows a graph of the latitude dependence of the zonal means in November, when ozone moves back from the mid-latitudes to the Polar region. In October 2015, the latitude region with TO values below the "climate normal" lay between $62.5^{\circ} \mathrm{S}$ and $85.0^{\circ} \mathrm{S}$. The TO over the whole region $\left(30^{\circ} \mathrm{S}-85^{\circ} \mathrm{S}\right)$ rose above $220 \mathrm{DU}$ by the end of November, and the ozonosphere above the Antarctic had fully recovered by 24 December.

\section{METHODOLOGY}

The increase in the ozone of the vortex ring can be attributed to the ozone transport from the polar region to the midlatitudes, but the zonal satellite data on the total ozone for this period are unavailable. The only observable facts are the quasi-steady existence of the ring with increased TO and the period of the back transport of ozone and filling up of the $\mathrm{AOH}$. The question arises: Is the ozone deficit in the $\mathrm{AOH}$ equal to the ozone excess in the ring? We constructed graphs of the latitude dependence of zonal TO averaged over time, $\Delta T$. The date when the first spring data on TO at the $85^{\circ} \mathrm{S}$ latitude were available according to [4] were taken as the starting point of the time interval. In 2014, that was 1 October. The final point of the $\Delta T$ interval was determined by the date when the ring began to fill (8 October). The validity of the choice of the $\Delta T$ interval was supported by the data on the ozone mass deficit at the web site [2]. Thus, for 2014, the time interval $\Delta T=8$ days.

The same approach was used to determine the limits of the $\Delta T$ interval in 2015. Graphs of the latitude dependence of the zonal TO were analyzed. The active processes of AOH filling in 2015 only began in early November, and the $\Delta T$ interval 
of the zonal TO averaging was $\Delta T=31$ days. That was likely associated with the activity of Calbuco Stratovolcano $\left(41.326^{\circ} \mathrm{S} ; 72.614^{\circ} \mathrm{W}\right)$, which is located in the Southern Andes (Chile). A large eruption of Calbuco (VEI=4) happened between 22 and 30 April 2015. The ash column was $10 \mathrm{~km}$ high. However, Calbuco was active for a year. As suggested by Zuev and Zueva [8], volcanic gases can cause depletion of the ozone layer.

An important aspect of the analysis of ozone redistribution is the choice of the TO threshold value, $X_{0}$. If the TO in a particular latitude region is higher than $X_{0}$, this region should be considered as having ozone surplus (+). Conversely, if the TO is lower than $X_{0}$, there is ozone deficit (-). Having processed satellite data on TO for 15 years, we experimentally found that the average annual total ozone between $32.5^{\circ} \mathrm{S}$ and $52.5^{\circ} \mathrm{S}$ should be taken as the threshold, $X_{0}$. For 2014, $X_{0}=302.8$ DU.

In Figure 2, the threshold, $X_{0}$, is shown with a dashed line, and the result of averaging zonal means at different latitudes, denoted as $x_{\varphi}$ over $\Delta T$, is shown with a solid line. In October, the region between $60^{\circ} \mathrm{S}$ and $85^{\circ} \mathrm{S}$ contains total ozone below the threshold, $X_{0}$, while in the region between $30^{\circ} \mathrm{S}$ and $60^{\circ} \mathrm{S}$, the TO is above $X_{0}$ (Fig. 2, a). The graph in Figure $1, a$ must be adjusted taking into account the spherical shape of the Earth, by multiplying the data in that graph by cosine latitude. The result is shown in Figure 2, $b$. In 2014, the ozone masses moving from the polar region to the mid-latitudes and back were equal to each other, reaching over 70 million tons, with the difference between (+) and (-) less than $4.9 \%$. No signs of ozone destruction were found in September - December 2014.

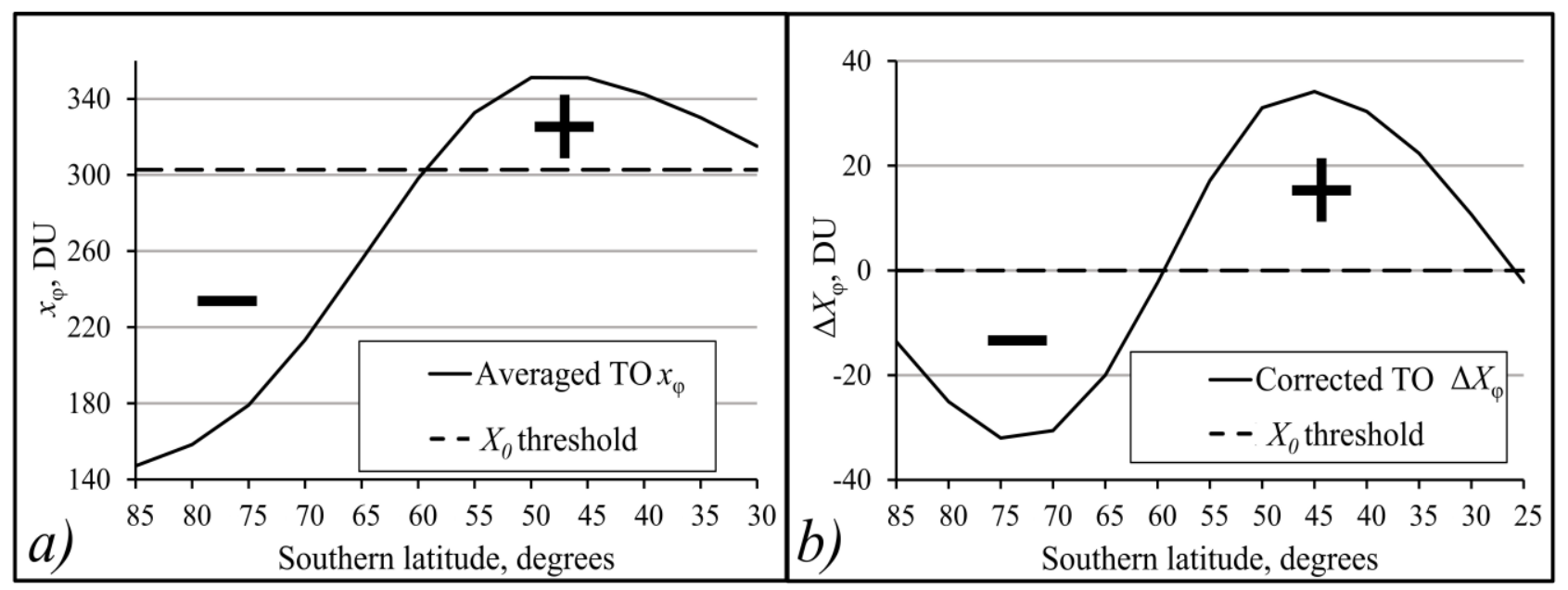

Figure 2. Deviation of the TO values in the polar region $(a)$ and mid-latitudes $(b)$ from the threshold in October 2014

Figure 3 shows the result of converting TO zonal means, $\Delta X_{\varphi}$, for 2015 , taking into account the spherical shape of the Earth. The threshold for $2015 X_{0}=296.5$ DU. In October, the ozone deficit in the polar region was higher than the ozone surplus in the mid-latitudes, and the difference reached $70.9 \%$.

The most likely reason for this was the destruction of the stratospheric ozone by the products of the eruption of Calbuco Volcano in Chile 22-30 April 2015. The eruption emissions can partially deplete the ozone in the Southern hemisphere and result in the mismatch between of the ozone deficit in the polar region and its excess in the middle latitudes. 


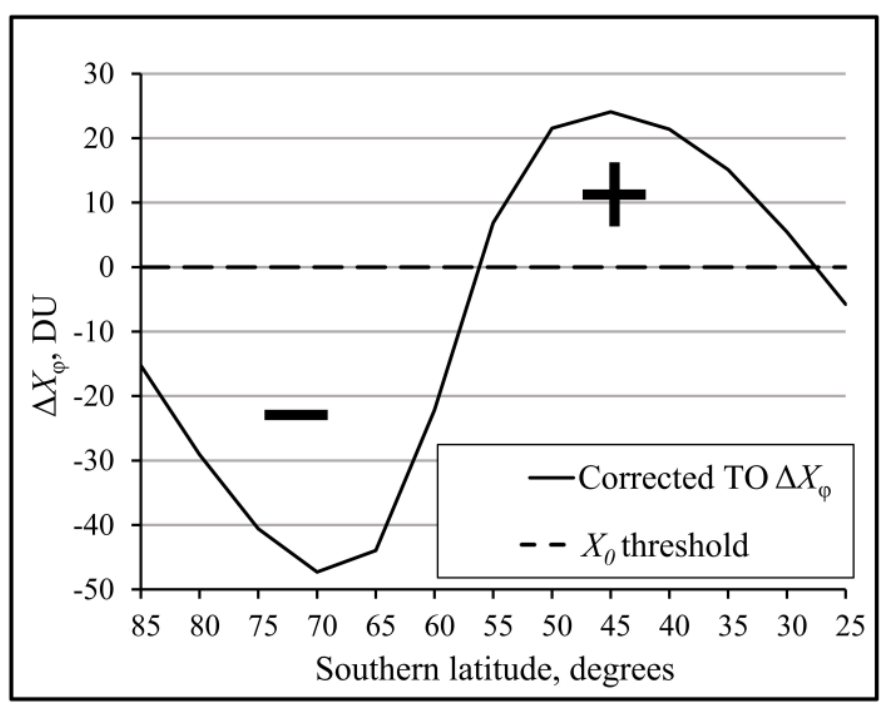

Figure 3. Ozone deficit and surplus in the region between $30^{\circ} \mathrm{S}$ and $85^{\circ} \mathrm{S}$ in October 2015

\section{CONCLUSIONS}

Estimates were obtained in 2014 to show that during the existence of the Antarctic ozone hole the ozone deficit in the polar region and its excess in the middle latitudes of the Southern Hemisphere practically coincide. The ozone masses moving from the polar region to the mid-latitudes and back were similar, reaching more than 70 million tons, with the difference between (+) and (-) less than 4.9\%. In 2015, there was every indication of ozone depletion, the difference between the ozone masses reached $70.9 \%$. Certainly, this was clearly associated with ozone destruction by volcanic gases given off by Calbuco Volcano.

\section{REFERENCES}

[1] Farman, J. C., Gardiner, B. G., Shanklin, J. D. "Large Losses of Total Ozone in Antarctica Reveal Seasonal $\mathrm{ClO} / \mathrm{NO}_{2}$ Interaction," Nature 315, 207-210 (1985).

[2] NASA, https://ozonewatch.gsfc.nasa.gov/meteorology/ (16 January 2019).

[3] McPeters, R., Kroon, M., Labow, G., Brinksma, E., Balis, D., Petropavlovskikh, I. et al. "Validation of the Aura Ozone Monitoring Instrument total column ozone product," J. Geophys. Res. 13, D15S14 (2008). doi:10.1029/2007JD008802.

[4] NASA, ftp://toms.gsfc. nasa.gov/ (21 January 2019).

[5] Stolarski, R. S., Schoeberl, M. R. "Further interpretation of satellite measurements of Antarctic total ozone," Geophys. Res. Lett. 13(12), 1210-1212 (1986).

[6] Kashkin, V. B., Rubleva, T. V., Khlebopros, R. G. [Stratosphere ozone: a view from space orbit], Krasnoyarsk, SFU, 218 pp. (2015) (in Russian).

[7] Kashkin, V. B., Rubleva, T. V., Dergunov, A. V. "Dynamics of the ozone anomaly in the Southern Hemisphere based on the data from the TOMS and OMI scanners," Proceedings of SPIE, 10466 (2017). doi:10.1117/12.2293210.

[8] Zuev, V. V., Zueva, N. E. "Volcanogenic variations in the stratosphere - the main regulator of the long-term behavior of the ozonosphere between 1979 and 2008," Optics of the atmosphere and ocean 24(1), 30-34 (2011) (in Russian). 